\title{
An experimental investigation of the independent effect of suction and degree of saturation on very small-strain stiffness of unsaturated sand
}

\author{
Arianna Pagano ${ }^{1, a}$, Alessandro Tarantino ${ }^{1}$, Meghdad Bagheri ${ }^{2}$, Mohammad Rezania $^{2}$,and Philippe Sentenac ${ }^{1}$ \\ ${ }^{1}$ EDP University of Strathclyde, Department of Civil and Environmental Engineering, Glasgow, UK \\ ${ }^{2} E D P$ Nottingham Centre for Geomechanics, University of Nottingham, Nottingham, UK
}

\begin{abstract}
The paper presents an experimental investigation of very small strain stiffness of unsaturated sand. A triaxial test apparatus was equipped with bender elements and compression discs in order to assess the stiffness at very small strains by measuring the velocity of propagation of shear and compression waves through an unsaturated sample. The negative water column method was adopted to apply suction at the base of the sample. The experiments were designed to investigate the independent effect of suction and degree of saturation on the wave propagation velocities. This was achieved by testing the sand sample on both the drying and wetting path.
\end{abstract}

\section{Introduction}

Stiffness is an essential characteristic of soil response and a critical parameter in geotechnical design. Soil stiffness exhibits a strong non-linear behaviour with strain level. Strains occurring in the ground for structures designed to be far from failure (Serviceability Limit State design) are generally small. Therefore, a better knowledge of stiffness parameters at small and very small strain level is important for realistic predictions of ground movements that may affect the performance of the geotechnical structure itself and the adjacent geotechnical structures. Furthermore, the small-strain analysis should take into account the unsaturated condition of the soil for the case where shallow geotechnical structures interact with the atmosphere. In these cases, the use of 'conventional' saturated soil stiffness parameters might lead to erroneous predictions of ground movement.

Bender element (BE) and compression disc (CD) methods, first developed by Shirley and Hampton (1978), are simple techniques to obtain small strain stiffness parameters by measuring the velocity of propagation of shear and compression waves through a soil sample. The paper presents an experimental investigation on the effect of unsaturated condition on small-strain stiffness of wellgraded sand under isotropic stress states via the propagation of mechanical waves. Bender element and compression disc tests have been carried out in a modified triaxial apparatus.

\section{Experimental setup and material properties}

A triaxial cell apparatus was modified by incorporating bender and compression elements into the pedestal and

a Corresponding author: arianna.pagano@strath.ac.uk top cap to transmit and receive mechanical waves respectively. A function generator and an oscilloscope allowed the input signal to be sent and both input and output signals to be recorded respectively. Figure 1 shows a schematic view of the modified triaxial platens and manufactured pieces for accommodation of bender elements and compression discs.

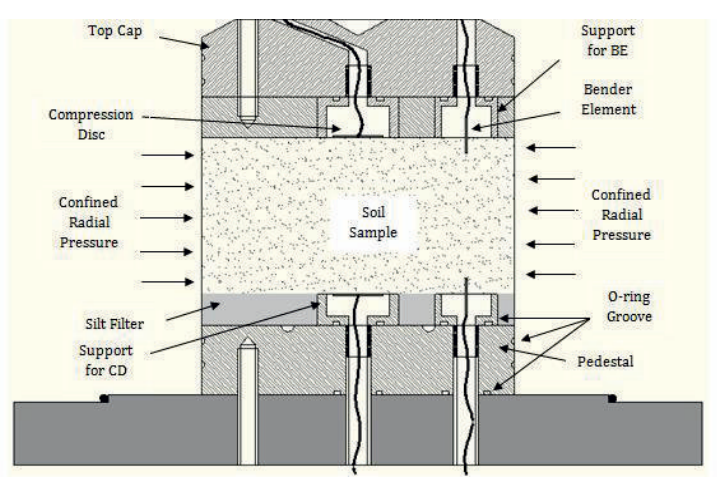

Figure 1. Schematic view of the modified triaxial base and platens (Bagheri 2011).

The tests were carried out on a cylindrical sand sample of $90 \mathrm{~mm}$ height and $100 \mathrm{~mm}$ diameter, with a well-graded particle size distribution. A well-graded particle size distribution leads to a well-graded pore size distribution and, hence, to a gradual desaturation process. A smoother water retention curve minimises differences in the degree of saturation between the top and the bottom of the sample. 
Table 1. Sample parameters.

\begin{tabular}{|c|c|c|}
\hline Height & 9.0 & $\mathbf{c m}$ \\
\hline Diameter & 10.0 & $\mathbf{c m}$ \\
\hline Total volume & 706.86 & $\mathbf{c m}^{\mathbf{3}}$ \\
\hline Specific gravity & 2.63 & - \\
\hline Dry density & 1.77 & $\mathbf{g} / \mathbf{c m}^{\mathbf{3}}$ \\
\hline Void ratio & 0.49 & - \\
\hline Porosity & 0.33 & - \\
\hline Dry mass & 1250.98 & $\mathbf{g}$ \\
\hline
\end{tabular}

A cylindrical $(10 \times 100 \mathrm{~mm})$ silt filter rather than a conventional porous stone was installed at the base to control pore-water pressure. The silt layer provides a high air-entry interface to allow transmission of the negative pore-water pressure while preventing the ingress of air into the water drainage system. Furthermore, it prevents the development of large pores at the sample/filter interface (wall effect) which is likely to occur in coarse grained materials. The filter was prepared using a crushing quartz stone known by the commercial name of Silica (mean particle size of $25.2 \mu \mathrm{m}$ ). The silt filter parameters are shown in Table 2.

Table 2. Silt filter parameters.

\begin{tabular}{|c|c|c|}
\hline Height & 1.0 & $\mathbf{c m}$ \\
\hline Base radius & 10.0 & $\mathbf{c m}$ \\
\hline Total volume & 78.54 & $\mathbf{c m}^{\mathbf{3}}$ \\
\hline Specific gravity & 2.7 & - \\
\hline Dry density & 1.24 & $\mathbf{g} / \mathbf{c m}^{\mathbf{3}}$ \\
\hline Void ratio & 1.16 & - \\
\hline Porosity & 0.54 & - \\
\hline Dry mass & 98 & $\mathbf{g}$ \\
\hline
\end{tabular}

Pore-water pressure inside the sample was controlled with the aid of a water reservoir connected to the bottom drainage of the sample. The negative water column method was used to consolidate the silt filter and to determine the soil water retention curve on both drying and wetting paths.

\section{Testing procedures}

\subsection{Silt filter preparation}

A $100 \mathrm{~mm}$ diameter cylindrical splitting mould was used to give the required shape to the sample and the silt filter. Filter paper was first placed on the pedestal in order to prevent silt loss through the hydraulic drainage. A latex membrane was placed inside the mould, fixed to the cell pedestal with two O-rings, stretched to the top of the mould and held open by applying a vacuum. A silt slurry $(w=500 \%)$ was gently poured into the mould and allowed to settle for 48 hours. The amount of silt used to prepare the slurry $(98 \mathrm{~g})$ was calculated in order to obtain a 10 $\mathrm{mm}$ thick filter. After sedimentation occurred, excess clear water was drained out of the mould by adjusting the water reservoir height until its water level was up to the top of the silt surface.

The negative water column method was used to consolidate the silt filter by applying suction up to approximately $6 \mathrm{kPa}$. Suction was applied in steps by lowering the water reservoir so that its water level was below the bottom of the silt filter. Consolidation was allowed upon each suction step until hydraulic equilibrium was reached. The consolidation process was monitored by recording the water exchange between the silt filter and the reservoir using a balance.

After applying the last suction step, the water reservoir was raised in steps until its water level was at the top of the silt filter.

\subsection{Sample preparation}

A sandy material was prepared by mixing different sizes of fine, medium and coarse grained sand. The required mass of sand for each diameter (sieve size) was calculated in order to obtain a well-graded grain size distribution by using a modified Fuller equation:

$$
P=\frac{\sqrt{\frac{D}{D_{\max }}}-\sqrt{\frac{D_{\min }}{D_{\max }}}}{1-\sqrt{\frac{D_{\min }}{D_{\max }}}} \times 100
$$

where $P$ is the passing percentage, $D$ is the anticipated grain (sieve) size, $D_{\max }$ is the maximum grain (sieve) size and $D_{\min }$ is the minimum grain (sieve) size. $D_{\max }$ and $D_{\min }$ were equal to $0.425 \mathrm{~mm}$ and $0.063 \mathrm{~mm}$ respectively. Particle size distribution is shown in Figure 2.

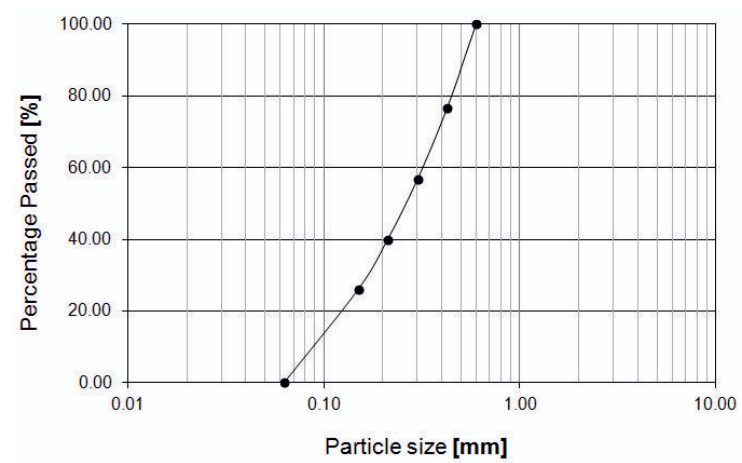

Figure 2. Well-graded particle size distribution

Once mixed, the material was oven-dried and placed into the mould with the aid of a specially manufactured pluviator in order to obtain a homogeneous, repeatable sample. A schematic view of the pluviator is shown in Figure 3 . The perforated plates and sieves were purposely designed to obtain a flat and even top surface of the sample after pluviation. With the two perforated plates misaligned ("closed" position), the upper part of the pluviator was filled with oven-dried sand. Then, the top perforated plate was allowed to slide and align with the bottom perforated plate ("open" position). Sand was then pluviated into the mould in four steps until a $90 \mathrm{~mm}$ height sample was obtained. The triaxial cell top cap was 
then covered with filter paper and placed on the top of the sample.

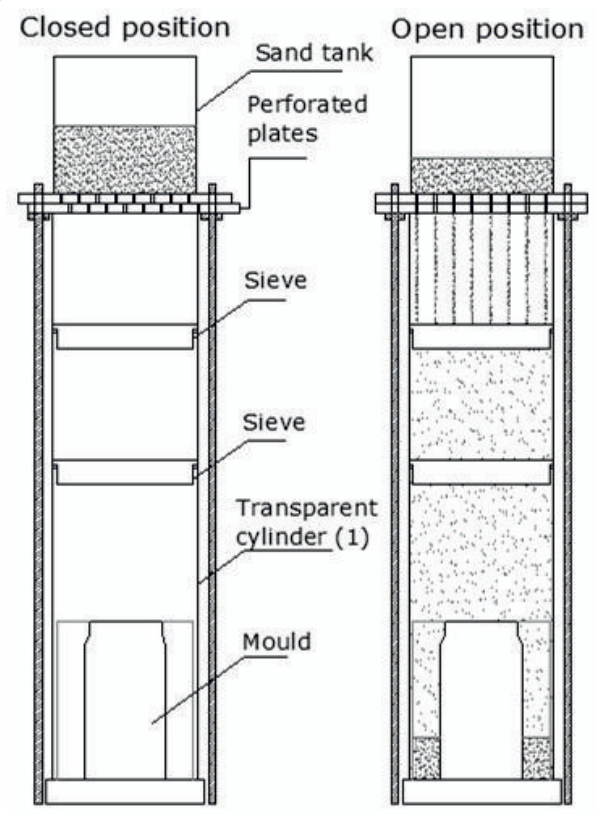

Figure 3. Schematic view of the purposely manufactured pluviator.

\subsection{Water retention curve development and BE/CD measurements}

After sample preparation, the relationship between suction and degree of saturation was assessed by using the negative water column method. The sample was first saturated by adjusting the water level up to the top of the sample. The amount of water needed to saturate the sample was recorded. Then, suction steps were applied by lowering the water reservoir. For each step, the change in mass of water in the reservoir due to the water exchange induced by the suction change was recorded using a balance and used to calculate the degree of saturation $S_{r}$ :

$$
S_{r}=\frac{M_{w}}{V_{t}-M_{d} / G_{s}} \times 100
$$

where $M_{w}$ is the mass of water in the sample, $V_{t}$ is the sample total volume, $M_{d}$ is the dry mass of sand and $G_{s}$ is the sample specific density.

The value of suction for each step was calculated as:

$$
s=(H-h) \times g
$$

where $s$ is the applied suction, $H$ is the distance between the top of the sample and the water level in the reservoir, $h$ is the sample height and $g$ is the acceleration due to gravity. The water retention behaviour was determined in a suction range between 0 and approximately $6 \mathrm{kPa}$ for both drying and wetting paths, under different stress conditions. At each suction step shear and compression wave measurements were taken after hydraulic equilibrium was reached. A sinusoidal input wave having a frequency of $5 \mathrm{kHz}$ was applied to the $\mathrm{BE}$ and $\mathrm{CD}$ transmitters. Output signals from $\mathrm{BE}$ and $\mathrm{CD}$ receivers were simultaneously recorded and then filtered in order to remove the background noise and enable identification of the first wave arrival. Once the wave travel time $\Delta t$ was determined, the wave velocity $V$ and the correspondent stiffness modulus $K$ (Shear or Young modulus) can be calculated as follows:

$$
\begin{gathered}
V=\frac{L_{t t}}{\Delta t} \\
K=\rho \times V^{2}
\end{gathered}
$$

where $L_{t t}$ is the travel length, usually considered as the tip-to-tip distance between the transmitter and the receiver bender element, and $\rho$ is the dry density of the soil. It is worth noting that the travel time $\Delta t$ was simply taken as the time distance between characteristic points of the input and output signals. The chosen characteristic point is the first peak (positive or negative) of the wave. The identification of the first arrival is however a crucial issue in bender and compression element tests interpretation. Although the simplified approach used in this research may lead to erroneous absolute values of stiffness moduli, it still allows identification of the relative effect of suction and degree of saturation.

\section{Experimental results}

Two tests were conducted on the same sample at two different stress state conditions. The first test was conducted on the unloaded sample (test I), which was left inside the mould while suction steps were applied. The second test was carried out under isotropic loading conditions by applying a cell pressure of $10 \mathrm{kPa}$ (test II). In order to make the sample self-standing before applying the cell pressure, the splitting mould was removed after the application of the last suction step on the unloaded sample. The triaxial cell was then assembled on the cell base and filled with de aired water. Water pressure inside the cell was then increased by means of a bladder (airwater interface) connected to a pressure panel.

\subsection{Unloaded sample}

Figure 4 shows the water retention curve obtained during test I. The unloaded condition led to a poor contact between the soil and the bender/compression elements. No waves could then be recorded by the oscilloscope.

\subsection{Loaded sample}

Figure 5 shows the degree of saturation plotted against the applied suction in test II. The soil stiffness parameters measured at some critical points are also reported in the figure. In particular, the stiffness is compared at the suction of about $3 \mathrm{kPa}$ along the drying and wetting path, i.e. same suction and different degree of saturation (points A and C). The stiffness is also compared at the degree of saturation of about $67 \%$ along the drying and wetting path, i.e. same degree of saturation and different suction (points B and C). 


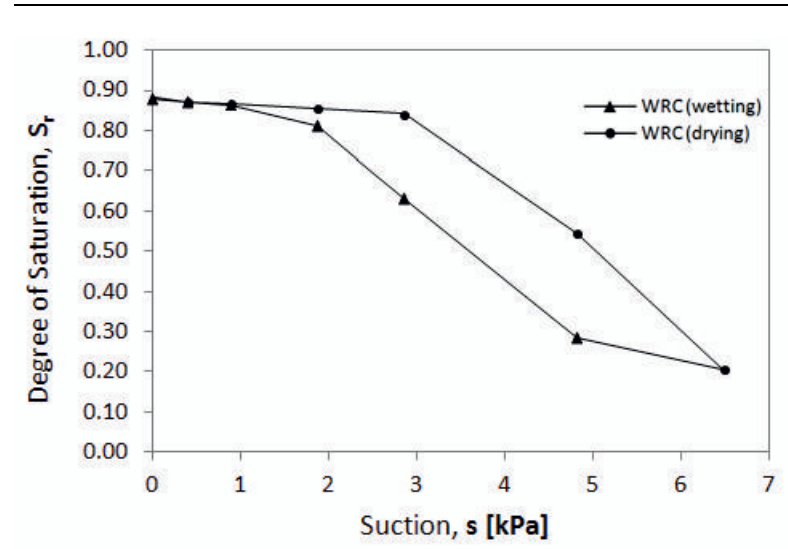

Figure 4. Variation of degree of saturation with applied suction in test $\mathrm{I}$, cell pressure $0 \mathrm{kPa}$ (drying and wetting paths).

As expected, the stiffness moduli increase from A to $\mathrm{B}$ along the drying path. From A to B, the suction increases and the degree of saturation decreases and it is difficult to discriminate between these two effects.

The role of degree of saturation appears to be clearer when comparing stiffness at same value of suction (points $\mathrm{A}$ and $\mathrm{C}$ ). The lower the degree of saturation (wetting path), the higher is the wave velocity and hence the soil stiffness. Measurements of stiffness along the entire drying and wetting paths (which are not reported in the figure) confirm this trend.

The role of suction appears to be clearer when comparing stiffness at same value of degree of saturation (points B and C). The higher the suction (drying path), the higher is the wave velocity and hence the soil stiffness. Measurements of stiffness along the entire drying and wetting paths (which are not reported in the figure) confirm this trend.

This evidence is in contrast with the common assumption that unsaturated soil stiffness is controlled by average skeleton stress $\sigma^{\prime \prime}$ (e.g. Alonso et al. 2010):

$$
\sigma^{\prime \prime}=\sigma+s \times S_{r}
$$

If this was the case, lower values of degree of saturation at the same value of suction (wetting path), which lead to lower values of average skeleton stress, should have led to lower (and not higher) values of stiffness.

On the other hand, at the same value of degree of saturation, the increase in stiffness associated with an increase in suction appears to be marginal. This seems to suggest that the degree of saturation has a dominant role on soil stiffness.

As regards the effect of cell pressure, a series of tests carried out at a cell pressure of $50 \mathrm{kPa}$ (not reported in the paper) have shown that the effect of partial saturation becomes less significant as the cell pressure (total isotropic stress) increases. This effect is somehow captured by Equation 6 as an increase in total stress tends to offset the effect of partial saturation.

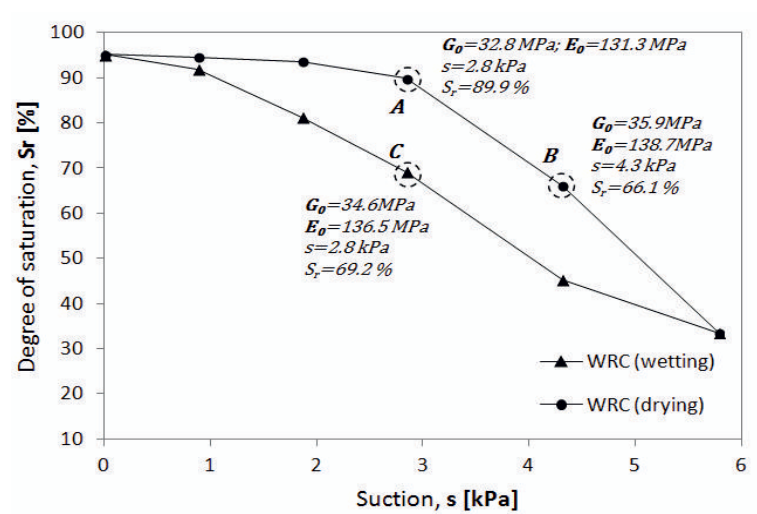

Figure 5. Variation of degree of saturation with applied suction and $\mathrm{BE} / \mathrm{CD}$ measurements in test II, cell pressure $10 \mathrm{kPa}$ (drying and wetting paths).

\section{Conclusions}

An experimental program has been carried out using a modified triaxial cell to investigate unsaturated soil behaviour in the very small strain range. Tests have been conducted on well-graded sand in order to investigate the independent effect of suction and degree of saturation on soil stiffness parameters.

The experimental study led to the conclusion that the effect of suction and degree of saturation on soil stiffness cannot be interpreted in terms of average skeleton stress. Although suction leads to an increment in soil stiffness, degree of saturation appears to have a dominant role. In addition, the effect of degree of saturation is not captured by the average skeleton stress, not even at qualitative level.

Further investigation is needed to identify a conceptual model capable of predicting the independent effect of suction and degree of saturation on very small strain stiffness.

\section{References}

1. Alonso EE, Pereira J-M, Vaunat J, and Olivella S (2010). A microstructurally based effective stress for unsaturated soils. Géotechnique, 60 (12): 913-925.

2. Bagheri M (2011). Small strain stiffness measurement of unsaturated sand using bender and compression elements. Unpublished MSc thesis, Department of Civil and Environmental Engineering, University of Strathclyde, Glasgow.

3. Shirley DJ, Hampton LD (1978). Shear-wave measurement in laboratory sediments. Journal of the Acoustical Society of America, 62(2): 607-613. 